\title{
EPIDEMIOLOGY OF ERECTILE DYSFUNCTION IN FOUR COUNTRIES: CROSS-NATIONAL STUDY OF THE PREVALENCE AND CORRELATES OF ERECTILE DYSFUNCTION
}

\author{
ALFREDO NICOLOSI, EDSON D. MOREIRA, JR, MASAFUMI SHIRAI, \\ MOHD ISMAIL BIN MOHD TAMBI, AND DALE B. GLASSER
}

\begin{abstract}
Objectives. To measure the prevalence of erectile dysfunction (ED) in community-based populations in Brazil, Italy, Japan, and Malaysia and to study its association with the demographic characteristics, medical conditions, and health-related behavior.

Methods. In each country, a random sample of approximately 600 men aged 40 to 70 years was interviewed using a standardized questionnaire. All the data were self-reported. ED was assessed by the participants' "ability to attain and maintain an erection satisfactory for sexual intercourse," and the men were classified as not having ED if they answered "always" and as having mild, moderate, or complete ED if they answered "usually," "sometimes," or "never," respectively.

Results. The age-adjusted prevalence of moderate or complete ED was 34\% in Japan, 22\% in Malaysia, $17 \%$ in Italy, and $15 \%$ in Brazil. The overall age-specific prevalence of moderate or complete ED was $9 \%$ for men aged 40 to 44 years, $12 \%$ for 45 to 49 years, $18 \%$ for 50 to 54 years, $29 \%$ for 55 to 59 years, 38\% for 60 to 64 years, and 54\% for those 65 to 70 years. The increased risk of ED was associated with diabetes, heart disease, lower urinary tract symptoms, heavy smoking, and depression and increased by $10 \%$ per year of age. It was inversely associated with education, physical activity, and alcohol drinking.

Conclusions. ED is an international problem, the prevalence and severity of which increases with age. Despite national variations in prevalence, uniform associations were found between ED and medical conditions and lifestyle habits. UROLOGY 61: 201-206, 2003. () 2003, Elsevier Science Inc.
\end{abstract}

$\mathrm{E}$ rectile dysfunction (ED), "the inability to attain and/or maintain an erection satisfactory for sexual intercourse," 1 is a common problem of middle-age and older men. The prevalence of ED has been described in some communities in the United States (Olmsted County, Minnesota, ${ }^{2}$ rural

\section{This work was partially funded by Pfizer Inc}

From the Department of Epidemiology, Institute of Biomedical Technologies, National Research Council, Milan, Italy; Gertrude H. Sergievsky Center, Columbia University School of Public Health, New York, New York; Gonçalo Moniz Research Center, Fundagão Oswaldo Cruz, Salvador, Brazil; Toho University School of Medicine, Chiba, Japan; Specialist Reproductive Research Center, National Population and Family Development Board, Ministry of Women and Family Development, Kuala Lumpur, Malaysia; and Pfizer Inc., New York, New York.

Reprint requests: Alfredo Nicolosi, M.D., Ph.D., Department of Epidemiology, Institute of Biomedical Technologies, National Research Council, Via Fratelli Cervi 93, Segrate, Milan 20090, Italy

Submitted: March 25, 2002, accepted (with revisions): August 5, 2002
New York State, ${ }^{3}$ and Massachusetts ${ }^{4}$ ); in a national sample ${ }^{5}$; in populations in Finland, ${ }^{6}$ Germany, ${ }^{7}$ Holland, ${ }^{8}$ Australia, ${ }^{9}$ Japan,,${ }^{10}$ Thailand, ${ }^{11}$ and Turkey, ${ }^{12}$ and in general practice patient populations. ${ }^{13-15}$ These results are difficult to compare because the investigators used different definitions of ED and sampled men within different age ranges. We undertook this cross-national survey using a single questionnaire to determine the prevalence and correlates of ED in diverse geographic, ethnic, and cultural populations.

\section{MATERIAL AND METHODS}

The study was a population-based survey of men aged 40 to 70 years in Brazil, Italy, Japan, and Malaysia conducted between October 1997 and June 1998. On the basis of previous estimates, we determined that a total sample size of 2400 men would be adequate to yield stable age-specific estimates of the prevalence of ED. The sampling of households in each country was conducted in such a way as to compensate for the proba- 
ble number of absences of eligible men and allow for nonresponses. All the sampled households were interviewed, and approximately 600 eligible men were included from each country.

A structured questionnaire was developed in consultation with the investigators, and two focus groups were held in each country to allow for adjustments reflecting local customs and culture. The method of data collection was different among the countries to elicit the most valid response given the cultural differences. The men were interviewed in person in Brazil, by telephone in Italy, by telephone and/or in person in Malaysia, and by means of self-administered, mailed questionnaires in Japan.

ED was assessed by a single question: "Using the following categories, how would you describe yourself?: Always/usually/ sometimes/never able to get and keep an erection adequate for satisfactory sexual intercourse." The responses were considered to represent "no ED," "mild ED," "moderate ED," and "complete ED," respectively. We focused on the men with moderate (ie, "sometimes able") or complete ED (ie, "never able"), because the "usually able" category may be a mix of men with intermittent situational problems or mild persistent ED. This conservative choice would underestimate the prevalence of ED.

The questionnaire included medical, anthropometric, sociodemographic, and lifestyle data. The information was selfreported and no attempt was made to validate respondents' answers with their medical records. The men were classified as having a specific disease if they reported having received a physician's diagnosis or if they were taking medications for the disease in question. Prostate conditions included benign prostatic hyperplasia, a history of prostatitis, prostate surgery, and prostate cancer. Lower urinary tract symptoms (LUTS) were assessed using the International Prostate Symptoms Score and classified as absent or minor (a score of 7 or less), moderate (score of 8 to 19), or severe (score of 20 to 35). ${ }^{16}$ Depressive symptoms were assessed by the shortened (5-item) Center for Epidemiologic Studies Depression Scale, ${ }^{17}$ with scores ranging from 5 to 20. A score 9 or greater (corresponding to the upper quintile) was used as indicative of the presence of depressive symptoms. Smokers included men who smoked tobacco and were classified as current or former smokers. Current smoking was analyzed on the basis of the number of tobacco units (cigarettes, cigars, pipes) consumed per day. The number of alcoholic drinks per week was calculated on the basis of the reported number of drinks of beer, wine, or spirit, weighted by the alcoholic content (beer $\times 0.4+$ wine + spirits $\times 2.5$ ). The degree of physical activity was classified as "less than average," "average," or "more than average," depending on the extent and frequency at work and during leisure time. Men were considered sexually active if they reported having sexual intercourse or masturbating at least once during the preceding 6 months.

The crude and age and country-adjusted odds ratios (ORs) were calculated for each covariate. Logistic regression analysis was used to estimate the association between ED and the other variables, adjusting for the simultaneous effect of all the variables in the model.

\section{RESULTS}

The response rate was $92 \%$ in Brazil, $72 \%$ in Italy, $51 \%$ in Japan, and $16 \%$ in Malaysia, for a total of 2513 men. Of this total, 2417 (96.2\%) answered the ED question. The prevalence of ED varied across countries, but the age distribution was similar (Fig. 1). Overall, the proportion of men who could "usually" achieve and maintain an erection

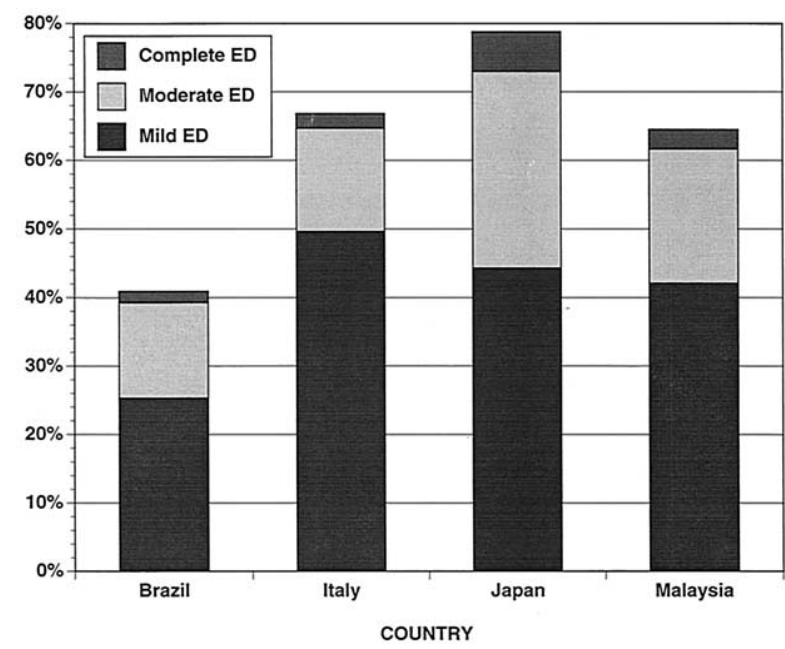

FIGURE 1. Age-standardized prevalence of ED by severity and country.

varied least across all age groups (between 30\% and 49\%). The proportion of men who could "sometimes" achieve and maintain an erection was approximately $10 \%$ until the age of 49 , when it steeply increased to $41 \%$ in the oldest age group. No men with complete ED were in the youngest age group, but the prevalence of complete ED was $4 \%$ between the age of 44 and 49 years and reached $13 \%$ after 65 years. The age-adjusted prevalence of moderate or complete ED was $34.5 \%$ in Japan, $22.4 \%$ in Malaysia, $17.2 \%$ in Italy, and $15.5 \%$ in Brazil (using the age distribution of the total sample population as the standard).

The age-adjusted prevalences of the demographic, social, medical, and lifestyle characteristics (with the exception of the proportion of single men) were different in the four countries, with at least one country different from the others $(P$ $<0.05$; Table I). Table II shows the prevalence of the characteristics or conditions listed in Table I among the men with and without ED and the crude and adjusted (by age and country) ORs. The association between men with ED and those who reported being single or having a diagnosis of diabetes, hypertension, heart disease, depression or depressive symptoms, prostate disease, or moderate or severe LUTS was positive. No association was found between ED and current smoking but, among current smokers, the OR was higher in heavy smokers. There was an inverse association between ED and increasing educational level, physical activity, and current alcohol drinking (although not statistically significant).

The multivariate logistic analysis showed that the risk of ED increased by almost $10 \%$ per year of age (Table III). The risk of ED varied across countries, even after controlling for individual characteristics. ED was associated with the duration of diabetes and heart disease (5\% per year of disease 
TABLE I. Characteristics of study population by country (absolute number of men and ageadjusted prevalence)

\begin{tabular}{|c|c|c|c|c|c|c|c|c|}
\hline \multirow[b]{2}{*}{ Characteristic or Condition } & \multicolumn{2}{|c|}{ Brazil } & \multicolumn{2}{|c|}{ Italy } & \multicolumn{2}{|c|}{ Japan } & \multicolumn{2}{|c|}{ Malaysia } \\
\hline & $\mathbf{n}$ & $\%$ & $\mathbf{n}$ & $\%$ & $\mathbf{n}$ & $\%$ & $\mathbf{n}$ & $\%$ \\
\hline \multicolumn{9}{|l|}{ Marital status } \\
\hline Married & 497 & 82.8 & 541 & 91.2 & 567 & 90.7 & 557 & 94.0 \\
\hline Widow, separated, divorced & 70 & 11.6 & 31 & 4.8 & 26 & 4.2 & 13 & 1.8 \\
\hline Single & 35 & 5.6 & 20 & 4.0 & 25 & 5.1 & 30 & 4.2 \\
\hline Sexually active & 587 & 97.1 & 567 & 99.2 & 531 & 88.8 & 575 & 92.1 \\
\hline Currently employed & 427 & 68.6 & 354 & 68.5 & 490 & 83.7 & 526 & 80.1 \\
\hline \multicolumn{9}{|l|}{ Education } \\
\hline High school not completed & 398 & 67.2 & 322 & 51.5 & 210 & 30.5 & 256 & 48.1 \\
\hline High school completed & 142 & 22.6 & 216 & 38.5 & 294 & 50.5 & 274 & 42.8 \\
\hline Degree & 62 & 10.1 & 53 & 10.1 & 112 & 19.0 & 62 & 9.1 \\
\hline Diabetes & 34 & 5.9 & 53 & 7.9 & 66 & 9.7 & 70 & 13.1 \\
\hline Hypertension & 154 & 26.1 & 133 & 19.3 & 146 & 21.1 & 107 & 19.8 \\
\hline Heart disease & 49 & 8.5 & 67 & 9.9 & 46 & 6.4 & 38 & 8.4 \\
\hline Ulcer & 48 & 8.1 & 97 & 15.6 & 120 & 18.7 & 30 & 5.5 \\
\hline Depression & 50 & 8.6 & 56 & 9.1 & 29 & 4.1 & 29 & 5.0 \\
\hline Depressive symptoms (CES-D) & 199 & 33.2 & 130 & 22.8 & 68 & 18.0 & 79 & 11.5 \\
\hline Prostate disease (any) & 45 & 8.2 & 82 & 11.8 & 45 & 6.3 & 11 & 2.0 \\
\hline \multicolumn{9}{|l|}{ LUTS } \\
\hline Absent or minor & 426 & 70.0 & 522 & 90.4 & 465 & 90.9 & 556 & 93.9 \\
\hline Moderate & 136 & 23.3 & 60 & 9.1 & 46 & 8.4 & 32 & 5.8 \\
\hline Severe & 39 & 6.7 & 3 & 0.6 & 4 & 0.7 & 1 & 0.4 \\
\hline \multicolumn{9}{|l|}{ Smoking status } \\
\hline Never & 173 & 28.2 & 187 & 32.2 & 92 & 15.1 & 256 & 43.6 \\
\hline Former smoker & 235 & 40.4 & 200 & 32.2 & 193 & 29.3 & 65 & 12.1 \\
\hline Current smoker & 193 & 31.4 & 203 & 35.6 & 321 & 55.6 & 269 & 44.4 \\
\hline \multicolumn{9}{|l|}{ Tobacco units per day (n) } \\
\hline None & 408 & 68.5 & 387 & 64.4 & 300 & 45.6 & 324 & 55.2 \\
\hline $1-30$ & 183 & 29.7 & 189 & 33.4 & 260 & 44.2 & 246 & 40.1 \\
\hline$>30$ & 11 & 1.9 & 14 & 2.2 & 57 & 10.2 & 29 & 4.7 \\
\hline \multicolumn{9}{|l|}{ Alcoholic drinks (n) } \\
\hline None & 191 & 33.0 & 136 & 23.2 & 190 & 29.8 & 493 & 82.1 \\
\hline $1-7 / \mathrm{wk}$ & 253 & 41.3 & 103 & 18.7 & 208 & 33.5 & 87 & 14.1 \\
\hline$\geq 8 / \mathrm{wk}$ & 158 & 25.7 & 353 & 58.1 & 223 & 36.7 & 19 & 3.8 \\
\hline \multicolumn{9}{|l|}{ Physical activity } \\
\hline Less than average & 52 & 9.3 & 44 & 6.7 & 118 & 19.8 & 40 & 9.6 \\
\hline Average & 89 & 14.6 & 167 & 27.4 & 178 & 28.4 & 110 & 18.5 \\
\hline More than average & 461 & 76.1 & 381 & 65.8 & 326 & 51.7 & 451 & 71.9 \\
\hline
\end{tabular}

duration), depression (either a history of diagnosed depression or current depressive symptoms), and heavy smoking. LUTS were associated with ED in a graded manner. The inverse association between ED, education level, alcohol use, and physical activity was confirmed.

The men were also asked whether they would consult a doctor or other health professional if they had ED. In Brazil, 90\% said "yes"; in Italy, Malaysia, and Japan, 89\%, 72\%, and 31\%, respectively, answered affirmatively. Of the 548 men who reported moderate or severe ED and answered this question, only 26 (5\%) had been previously treated: 17 (19\%) of 89 in Brazil, 6 (6\%) of 97 in Malaysia, 3 (2\%) of 123 in Italy, and $0(0 \%)$ of 239 in Japan. When asked how comfortable they were in discussing their ED problem with a physician, 13\% in Brazil, 25\% in Italy, $57 \%$ in Japan, and 25\% in Malaysia said they were not at ease.

\section{COMMENT}

The results of this study contribute information on the prevalence of ED and confirm that it is a widespread problem among mature men, regardless of epidemiologic, ethnic, or environmental diversities. The prevalence of ED varied among the countries, but its age pattern and associations with background diseases and behaviors were similar.

The country-specific risk may reflect the influence of factors such as genetics (which we did not study) or cultural differences in the perception of, 
TABLE II. Association between moderate or severe erectile dysfunction and sociodemographic, medical, and lifestyle characteristics: crude and adjusted (by age and country) odds ratios

\begin{tabular}{|c|c|c|c|c|c|c|c|c|}
\hline \multirow[b]{2}{*}{ Characteristic or Condition } & \multicolumn{2}{|c|}{$\begin{array}{l}\text { Patients with } \\
\text { ED }\end{array}$} & \multicolumn{2}{|c|}{$\begin{array}{c}\text { Patients } \\
\text { Without ED }\end{array}$} & \multicolumn{2}{|c|}{ Odds Ratio } & \multicolumn{2}{|c|}{$95 \% \mathrm{CI}$} \\
\hline & $\mathbf{n}$ & $\%$ & $\mathrm{n}$ & $\%$ & Crude & Adjusted & $\mathrm{LCL}$ & $\mathrm{UCL}$ \\
\hline \multicolumn{9}{|l|}{ Marital status } \\
\hline Married & 493 & 88.8 & 1669 & 89.9 & 1 & 1 & & \\
\hline Widower, separated, divorced & 37 & 6.7 & 103 & 5.5 & 1.22 & 1.31 & 0.85 & 2.02 \\
\hline Single & 25 & 4.5 & 85 & 4.6 & 1.00 & 1.85 & 1.12 & 3.05 \\
\hline Absence of sexual activity & 77 & 14.5 & 42 & 2.3 & 7.31 & 3.88 & 2.55 & 5.91 \\
\hline Currently employed & 327 & 58.9 & 1470 & 79.1 & 0.38 & 0.77 & 0.59 & 1.00 \\
\hline \multicolumn{9}{|l|}{ Education } \\
\hline High school not completed & 321 & 57.9 & 874 & 47.1 & 1 & 1 & & \\
\hline High school completed & 187 & 33.8 & 739 & 39.8 & 0.69 & 0.71 & 0.56 & 0.90 \\
\hline Degree & 46 & 8.3 & 243 & 13.1 & 0.52 & 0.47 & 0.32 & 0.69 \\
\hline Diabetes & 88 & 16.0 & 135 & 7.3 & 2.42 & 1.96 & 1.43 & 2.70 \\
\hline Hypertension & 178 & 32.3 & 362 & 19.5 & 1.97 & 1.45 & 1.15 & 1.84 \\
\hline Heart disease & 81 & 14.7 & 119 & 6.4 & 2.51 & 1.81 & 1.30 & 2.53 \\
\hline Ulcer & 98 & 17.9 & 197 & 10.6 & 1.82 & 1.31 & 0.97 & 1.76 \\
\hline Depression & 60 & 10.8 & 104 & 5.6 & 2.05 & 2.21 & 1.53 & 3.21 \\
\hline Depressive symptoms (CES-D) & 129 & 29.7 & 347 & 20.2 & 1.67 & 2.27 & 1.74 & 2.96 \\
\hline Prostate disease (any) & 76 & 13.8 & 107 & 5.8 & 2.61 & 1.69 & 1.19 & 2.40 \\
\hline \multicolumn{9}{|l|}{ LUTS } \\
\hline Absent or minor & 380 & 77.4 & 1589 & 88.3 & 1 & 1 & & \\
\hline Moderate & 90 & 18.3 & 184 & 10.2 & 2.05 & 2.05 & 1.49 & 2.82 \\
\hline Severe & 21 & 4.3 & 26 & 1.4 & 3.38 & 5.75 & 2.93 & 11.30 \\
\hline \multicolumn{9}{|l|}{ Smoking status } \\
\hline Never & 143 & 26.3 & 565 & 30.7 & 1 & 1 & & \\
\hline Former smoker & 179 & 32.9 & 514 & 27.9 & 1.38 & 0.90 & 0.68 & 1.20 \\
\hline Current smoker & 222 & 40.8 & 764 & 41.5 & 1.15 & 1.03 & 0.79 & 1.34 \\
\hline \multicolumn{9}{|l|}{ Tobacco units per day (n) } \\
\hline None & 331 & 60.1 & 1088 & 58.6 & 1 & 1 & & \\
\hline $1-30$ & 183 & 33.2 & 695 & 37.4 & 0.87 & 1.00 & 0.80 & 1.26 \\
\hline$>30$ & 37 & 6.7 & 74 & 4.0 & 1.64 & 1.74 & 1.11 & 2.74 \\
\hline \multicolumn{9}{|l|}{ Alcoholic drinks (n) } \\
\hline None & 237 & 42.7 & 773 & 41.6 & 1 & 1 & & \\
\hline $1-7 /$ wk & 139 & 25.0 & 512 & 27.5 & 0.89 & 0.70 & 0.59 & 1.03 \\
\hline$\geq 8 / \mathrm{wk}$ & 179 & 32.3 & 574 & 30.9 & 1.02 & 0.81 & 0.60 & 1.05 \\
\hline \multicolumn{9}{|l|}{ Physical activity } \\
\hline Less than average & 97 & 17.5 & 157 & 8.4 & 1 & 1 & & \\
\hline Average & 151 & 27.2 & 393 & 21.1 & 0.62 & 0.70 & 0.50 & 1.00 \\
\hline More than average & 307 & 55.3 & 1312 & 70.5 & 0.38 & 0.55 & 0.40 & 0.75 \\
\hline
\end{tabular}

attitudes toward, and willingness to report, ED. The difference in prevalence may also have been a result of the different ways in which the questionnaire was administered. The method of administration was chosen with the aim of obtaining valid answers in the most suitable way for each country.

There is no simple answer to explain the low response rate in Malaysia and Japan. The most plausible explanation calls for the influence of cultural factors. However, the different response rates cannot influence the study of the association between ED and possible risk factors because the survey was presented to potential subjects as a survey of the general health of adult men. As in every epidemiologic study—particularly those dealing with sensitive questions-the results are subject to a certain degree of inaccuracy, but, rather than a random variation in reporting ED prevalence, it could be expected that the prevalence would be underreported. Our findings are consistent with the available epidemiologic and biologic evidence and are strengthened by the internal validity of the study, which comes from the use of a common questionnaire, the four-step scale in the definition of ED, and the linear trends of the association between ED and health-related factors. The major limitation of the study was that the data collection was limited to self-reports. Medical conditions that 


\begin{tabular}{|c|c|c|}
\hline Characteristic & $\begin{array}{l}\text { Odds } \\
\text { Ratio }\end{array}$ & $95 \% \mathrm{CI}$ \\
\hline Age (per 1-yr increase) & 1.10 & $1.08,1.11$ \\
\hline \multicolumn{3}{|l|}{ Education } \\
\hline High school not completed & 1 & \\
\hline High school completed & 0.73 & $0.56,0.96$ \\
\hline Degree & 0.52 & $0.34,0.80$ \\
\hline \multicolumn{3}{|l|}{ Country } \\
\hline Brazil & 1 & \\
\hline Italy & 1.60 & $1.10,2.33$ \\
\hline Malaysia & 2.16 & $1.45,3.24$ \\
\hline Japan & 5.38 & $3.58,8.07$ \\
\hline Diabetes (per 1-yr duration) & 1.05 & $1.01,1.10$ \\
\hline Heart disease (per 1-yr duration) & 1.05 & $1.01,1.09$ \\
\hline $\begin{array}{l}\text { Depression/depressive } \\
\text { symptoms }\end{array}$ & 2.09 & $1.60,2.74$ \\
\hline \multicolumn{3}{|l|}{ LUTS (IPSS score) } \\
\hline Absent or minor $(<8)$ & 1 & \\
\hline Moderate (8-19) & 1.80 & $1.28,2.54$ \\
\hline Severe $(\geq 20)$ & 4.56 & $2.24,9.27$ \\
\hline \multicolumn{3}{|l|}{ Tobacco units per day (n) } \\
\hline None & 1 & \\
\hline $1-30$ & 0.95 & $0.73,1.24$ \\
\hline$>30$ & 2.12 & $1.26,3.56$ \\
\hline \multicolumn{3}{|l|}{ Alcoholic drinks (n) } \\
\hline None & 1 & \\
\hline $1-7 /$ wk & 0.74 & $0.53,1.02$ \\
\hline$\geq 8 / \mathrm{wk}$ & 0.73 & $0.53,0.99$ \\
\hline \multicolumn{3}{|l|}{ Physical activity } \\
\hline Less than average & 1 & \\
\hline Average & 0.81 & $0.54,1.22$ \\
\hline More than average & 0.64 & $0.45,0.92$ \\
\hline
\end{tabular}

KEY: $C I=$ confidence interval; LUTS = lower urinary tract symptoms; IPSS = International Prostate Symptom Score.

may be asymptomatic are often unknown by the subject and consequently underreported, which is likely to lead to a nondifferential misclassification and the attenuation of the OR. The negative association between education and ED can be understood if we consider lower education as a marker of a high prevalence of undiagnosed diseases.

In agreement with previous studies, ${ }^{2-11,13-15}$ our results confirm that ED is associated with age but not an inevitable outcome of the aging process. Among the men aged 65 years or older, only 29\% reported moderate or complete ED in Brazil versus $71 \%$ in Japan.

In addition to aging, ED is associated with medical and behavioral conditions. Two studies of diabetic patients reported a prevalence of ED ranging from $35 \%$ to $75 \% .{ }^{18,19}$ We found that the risk of ED increased with the duration of diabetes, a finding observed in other studies. ${ }^{19,20}$ ED is most com- monly a vascular disorder, ${ }^{21,22}$ an etiology that is supported by our finding that it was more prevalent in men with heart disease and hypertension. Prostate disease or surgery have repeatedly been associated with ED, ${ }^{9,23}$ and we found that a history of prostate disease and the presence and severity of LUTS were associated factors. Depression and sexual dysfunction are often reported as associated conditions, with some investigators considering depression an important factor in the etiology of $\mathrm{ED},{ }^{24}$ and others stressing the role of ED in causing or exacerbating depressive symptoms. ${ }^{25}$ The association between heavy smoking and ED is consistent with the results of previous studies. ${ }^{26,27}$

Alcohol consumption inversely correlated with ED in our population. The Health Professionals Follow-up Study found a lower prevalence of ED in moderate drinkers than in nondrinkers or heavy drinkers. ${ }^{28}$ However, the Italian general practicebased study did not find any association, ${ }^{14}$ and the Massachusetts Male Aging Study found a slightly high prevalence of ED among alcohol consumers. ${ }^{4}$ Moderately active and active men had a lower prevalence of ED, and the beneficial effect of physical activity on ED has also been shown in other studies. ${ }^{27,28}$

Most of the men complaining of ED did not seek medical attention. A major cause for that can be the reluctance to admit to this disorder. There was a difference among the studied countries that leads us to believe that local culture plays an important role. This study was carried out before oral therapy with sildenafil was available. It will be interesting to see whether the observed pattern will change after the introduction of this treatment.

\section{CONCLUSIONS}

Although the prevalence of ED varied across the four countries, it was common in all of them and increased in prevalence and severity with age. Despite the national variations in the prevalence of medical conditions and health-related behaviors, clear associations emerged between ED and other factors. To define the risk for ED better, future studies should also examine the medical correlates of ED (especially those that are frequently asymptomatic or underdiagnosed) in prospective samples.

\section{REFERENCES}

1. NIH Consensus Conference: Impotence: NIH Consensus Development Panel on Impotence. JAMA 270: 83-90, 1993.

2. Panser LA, Rhodes T, Girman CJ, et al: Sexual function of men ages 40 to 79 years: the Olmsted County Study of Urinary Symptoms and Health Status Among Men. J Am Geriatr Soc 43: 1107-1111, 1995. 
3. Ansong KS, Lewis C, Jenkins $\mathrm{P}$, et al: Epidemiology of erectile dysfunction: a community-based study in rural New York State. Ann Epidemiol 10: 293-296, 2000.

4. Feldman HA, Goldstein I, Hatzichristou DG, et al: Impotence and its medical and psychosocial correlates: results of the Massachusetts Male Aging Study. J Urol 151: 54-61, 1994.

5. Laumann EO, Paik A, and Rosen RC: Sexual dysfunction in the United States: prevalence and predictors. JAMA 281: 537-544, 1999.

6. Koskimaki J, Hakama M, Huhtala $\mathrm{H}$, et al: Effect of erectile dysfunction on frequency of intercourse: a population based prevalence study in Finland. J Urol 164: 367-380, 2000.

7. Braun M, Wassmer G, Klotz T, et al: Epidemiology of erectile dysfunction: results of the "Cologne Male Survey." Int J Impot Res 12: 305-311, 2000.

8. Blanker MH, Bosch JL, Groeneveld FP, et al: Erectile and ejaculatory dysfunction in a community-based sample of men 50 to 78 years old: prevalence, concern, and relation to sexual activity. Urology 57: 763-768, 2001.

9. Pinnock CB, Stapleton AM, and Marshall VR: Erectile dysfunction in the community: a prevalence study. Med J Aust 171: 353-357, 1999.

10. Marumo K, Nakashima J, and Murai M: Age-related prevalence of erectile dysfunction in Japan: assessment by the International Index of Erectile Function. Int J Urol 8: 53-59, 2001.

11. Thai Erectile Dysfunction Epidemiologic Study Group (TEDES): An epidemiological study of erectile dysfunction in Thailand (Part 1: Prevalence). J Med Assoc Thai 83: 872-879, 2000 .

12. Akkus E, Kadioglu A, Esen A, et al: Prevalence and correlates of erectile dysfunction in Turkey: a populationbased study. Eur Urol 41: 298-304, 2002.

13. Dunn KM, Croft PR, and Hackett GI: Sexual problems: a study of the prevalence and need for health care in the general population. Fam Pract 15: 519-524, 1998.

14. Parazzini F, Menchini Fabris F, Bortolotti A, et al: Frequency and determinants of erectile dysfunction in Italy. Eur Urol 37: 43-49, 2000.

15. Chew K, Earle A, Stuckey B, et al: Erectile dysfunction in general medicine practice: prevalence and clinical correlates. Int J Impot Res 12: 41-45, 2000.
16. Barry MJ, Fowler FJ Jr, O'Leary MP, et al, for the Measurement Committee of the American Urological Association: The American Urological Association symptom index for benign prostatic hyperplasia. J Urol 148: 1549-1557, 1992.

17. Weissman MM, Sholomskas D, Pottenger M, et al: Assessing depressive symptoms in five psychiatric populations: a validation study. Am J Epidemiol 106: 203-214, 1977.

18. McCulloch DK, Campbell IW, Wu FC, et al: The prevalence of diabetic impotence. Diabetologia 18: 279-283, 1980.

19. Fedele D, Coscelli C, Cucinotta D, et al: Incidence of erectile dysfunction in Italian men with diabetes. J Urol 166: 1368-1371, 2001.

20. Bacon C, Hu F, Glasser D, et al: Duration of diabetes and risk of erectile dysfunction among older men. Diabetes 50(suppl 2): A456, 2001.

21. Virag R, Bouilly P, and Frydman D: Is impotence an arterial disorder? A study of arterial risk factors in 440 impotent men. Lancet 1: 181-184, 1985.

22. Sullivan ME, Keoghane SR, and Miller MA: Vascular risk factors and erectile dysfunction. BJU Int 87: 838-845, 2001.

23. Stanford JL, Feng Z, Hamilton AS, et al: Urinary and sexual function after radical prostatectomy for clinically localized prostate cancer: the Prostate Cancer Outcomes Study. JAMA 283: 354-360, 2000.

24. Jacobs JA, Fishkin R, Cohen S, et al: A multidisciplinary approach to the evaluation and management of male sexual dysfunction. J Urol 129: 35-38, 1983.

25. Shabsigh R, Klein LT, Seidman S, et al: Increased incidence of depressive symptoms in men with erectile dysfunction. Urology 52: 848-852, 1998.

26. Mannino DM, Klevens RM, and Flanders WD: Cigarette smoking: an independent risk factor for impotence? Am J Epidemiol 140: 1003-1008, 1994.

27. Johannes C, Araujo A, Feldman $\mathrm{H}$, et al: Incidence of erectile dysfunction in men 40 to 69 years old: longitudinal results from the Massachusetts Male Aging Study. J Urol 163: 460-463, 2000.

28. Derby CA, Mohr BA, Goldstein I, et al: Modifiable risk factors and erectile dysfunction: can lifestyle changes modify risk? Urology 56: 302-306, 2000. 